
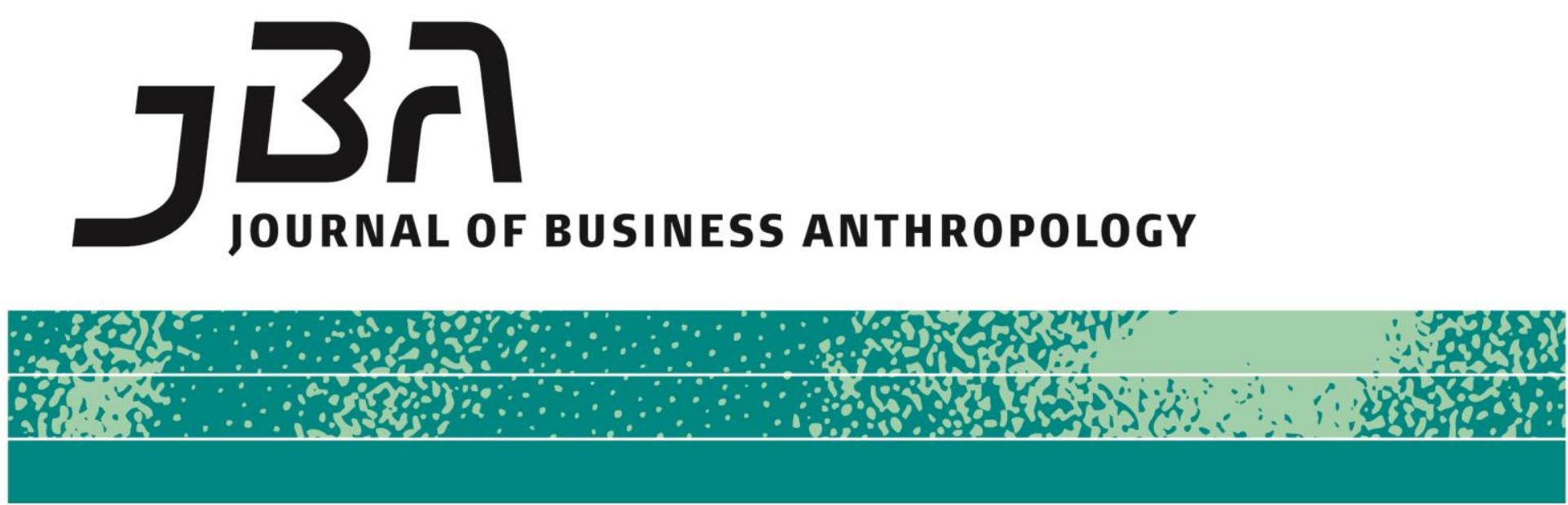

\title{
Business Ethics as an Ethical Self-Promotion? How Advertising Executives Promote their Activity
}

Léa Porée

\begin{abstract}
In this paper, I suggest that we untangle the business ethics of a French advertising agency as a social critique of the advertising field. I attempt to analyse the display and promotion of values used in order to enhance the agency's activity. Is the agency's business ethics simply a form of commodification and a marketing strategy? Or is it an attempt to introduce morality into a business that is supposedly not moral? I also intend to highlight the way that employees understand and negotiate this entrepreneurial discourse. Ethics has multiple purposes: it is a communication tool that promotes the agency itself, and it serves as a guarantee for good advertising practice. The study of business ethics in the agency emphasizes how the firm reconciles its entrepreneurial logic with the moral values it claims.
\end{abstract}

\section{Keywords:}

France, Advertising agency, Self-promotion, Commodification, Business ethics

Page 1 of 11

JBA Special Issue 3: 54-64, Spring 2016

(C) The Author(s) 2016 ISSN 2245-4217

www.cbs.dk/jba 


\section{Introduction: values displayed in plain view}

What are we to think of a graffiti showing the portrait of the iconic French leftist activist Stéphane Hessel on the door of an advertising agency? DVL Extensive $^{1}$ is a group comprising an advertising agency and a communication agency, with 200 employees, sharing the same premises in a working class area of Paris called Clichy, in the 17th district. The graffiti was painted on the agency's door during the period when Hessel's renowned essay Indignez-vous! $!^{2}$ was highly covered by the media and aroused great public attention. The agency staff did not know if the taggers knew that it was an advertising agency, but this civil act, according to my interpretation, by its sole presence, could be seen as an attack on advertising as the representative of capitalism. During an interview, Laurent, President of the agency, said with a smile: "in the end it doesn't bother us that it is here." The fact they did not remove the graffiti shows the use, or at least, a social reappropriation by DVL of an attack against the system as the stigma is overturned and made positive. If this tag might initially have tarnished the image of the agency, it has now, with the passing years, become an integral part of the agency's selfimage. Its promotion is based on small details which do not necessarily have a purpose in themselves when considered independently of one another, but, when assembled end to end, they form a managerial intention of the firm.

DVL's business ethics aim to show the values that advertising executives wish to present about themselves. The continued presence of the graffiti, for example, extends the agency's presentation of itself as open-minded and committed (compared to other advertising agencies). Here the advertising profession is shown as having positive values, such as open-mindedness and commitment. Anne Salomon in Moraliser le capitalisme (2009) stresses the "fashion phenomenon"3 that constitutes business ethics and its "advertising expression." However, viewing the DVL case as one of a mere "economisation" of ethics as defined by Anne Salomon (2004) would be an exaggeration since she would argue that ethics would be a meaningless and valueless product for the agency, and that the transfer of moral values in the actual economic context would be but a pretext for maximizing capital.

I do not consider the notion of "business ethics"-a category set up by the management in the 1970s and which has been on the rise ever since-as equivalent to the notion of "corporate culture," defined as the "firm's internal characteristics which unite it by its practices and

\footnotetext{
${ }^{1}$ All names mentioned in this article, including that of the agency, have been replaced by pseudonyms.

2 Translated into English as Time for outrage! (Hessel 2011).

${ }^{3}$ All translations from the original French references are by the author.
} 
distinguish it from other firms" (Bartoli and Hermel 1986: 244). ${ }^{4}$ These notions are management tools for firms: "business ethics as corporate culture seem to be avatars of this conceptual migration between social sciences and philosophy, on the one hand, and managerial speech, on the other" (Gallenga 2013: 33).

This category of business ethics as understood by managerial sciences raises two essential problems. On the one hand, it reifies and essentializes ethics by creating charters to which the employees must conform; there is the idea that ethics is to be found in the charters. The managers endow the charter with an independent status above individuals. Business ethics, as seen by the management, would make the employees act by dictating to them the tenets of good behaviour. On the other hand, there would be a second problem if those categories were adopted as such, without questioning, or trying to make explicit, what is implicit in them.

My goal here, therefore, is to consider business ethics from an anthropological point of view: that is, the display and promotion of values by the firm but also the reappropriation of these values by the actors, understood as managerial speech constructed as an anthropological category (Both 2007). It is a question of "anthropologising" business ethics (Gallenga 2013: 33), in order to show that it is more than a framing of professional practice since it is also a process of constant negotiation for the individuals. I intend to describe the business ethics of the agency and show how it is used as a tool to promote the image of the company. How do agency staff promote themselves as a collectivity? I will show the reconciliation between moral and market values and the commodification of business ethics, that is to say that business ethics itself becomes a product of the firm, which singularises it in a competitive advertising landscape.

\section{An advertising ethical self-promotion}

DVL's business, in my opinion, is a matter of a reconciliation between particular values and the economic requirements peculiar to the firm's environment. The geographical situation of the agency, the organisation of certain events, and its methods of work are just so many elements that constitute the abiding desire of the firm to demonstrate that advertising executives have values and ethics.

\footnotetext{
4 The term "culture" when used by management has been taken out of the context and vocabulary belonging to anthropology. According to Gallenga, the idea of a firm's culture is "conceptual abuse" (1993:145). She explains that the management uses this notion while underestimating all the theory attached to the concept of culture and therefore employs anthropological categories as rituals, myths, and so on, by modelling them on the firm's field without taking necessary methodological precautions.
} 
Within DVL, different services co-exist: account services elaborates the strategy it thinks the client should adopt and sells it the ideas thought up by the creative department, which is in charge of developing ideas for the advertisements to be used. DVS's communication department deals with the agency's public image.

A few months before I arrived, the communication department, consisting of only two people (Agnès, its manager for the past ten years, and Judith, the public relations officer, for the past seven), organized an event named "Clichy Extensive." The idea for this event came into being after they recognized that the agency, which employs two hundred people, has real financial impact on the neighbourhood since its employees go out to eat, have a drink, or shop in the vicinity. In order to get better acquainted with the people they encountered there every day, the communication department invited some of their clients, ${ }^{5}$ together with some shopkeepers from the area. "Clichy Extensive" was also intended to enhance the image of the Clichy district by exhibiting portraits of twelve emblematic and very popular shopkeepers whom the agency wanted to be seen as "representative" of the district. Clichy, in the 17 th District, is often thought of by Parisians as an area frequented by drug dealers, prostitutes, pickpockets, and other asocial elements. Agnès and Judith told me that they no longer wanted people to think about the cliché of the area as being dangerous. That is why they displayed portraits of emblematic shopkeepers and local initiatives. ${ }^{6}$ In this way, the agency put itself in a positive light: as a source of creative ideas, and as part of the diversity and social mix inherent in the representation of Clichy as a multicultural, bustling community. ${ }^{7}$ A booklet recounting that day was eventually edited in-house by the agency in order to send it out to clients, together with annual good wishes, and to distribute it among employees. An extract from the preface reads:

Clichy is our cooking pot, the melting pot of new ideas, the source of our creativity [...] If its history affects us to such an extent, it is because it looks like our own history, a little world full of life, made up of people from the four corners of the world, of different cultures of varied and complementary experiences, many languages-written, spoken or digital-a world tingling with ideas [...] We were overjoyed to discover

\footnotetext{
5 The clients designate the advertisers: the firms or labels for whom the agency advertises.

${ }^{6}$ For example, the only barber woman in Paris, the CEO of a shop called Tati, famous in France for its low prices.

${ }^{7}$ Similar particularities of the dramatization of a space of otherness in the city of Paris can be found in the areas of La Goutte D'or and Barbès-Rochechouart (Palumbo 2014). As Emanuelle Lallement (2005:134) has pointed out, "in Barbès, it is precisely the popularization of the difference that is the stock in trade, and it forms the social pattern one designates by this name."
} 
what draws us together and especially our mutual passion for man's diversity.

Beyond the production of the emblems of the neighbourhood, there is the desire to claim the geographical location of the agency and to include it in a series of positive ideas. This positioning in the city is significant because it extends the vision that advertising executives wish to give of themselves. The agency itself becomes an emblem of diversity and openmindedness in the heart of the district. The name "Clichy Extensive" itself, putting the name of the neighbourhood (Clichy) together with part of the agency's name (Extensive), reminds us that the agency is an emblematic component of the neighbourhood to the same extent as the other emblems of the area (for example, the twelve shopkeepers). The agency's values, therefore, become part of the values of the district as seen by its employees. Further on in the booklet, one can read: "we, too, are some of these men and women who write the history of Clichy, this territory where we tread the pavements leading to our agency." The agency's executives embody the same spirit as the symbolic people of the district. Judith, the PR manager, speaks of the agency as having a certain status in the district owing to the architecture of its building. In this respect, during my fieldwork I noticed that a lot of people-including tourists, neighbours and passers-by-stopped in front of the premises to photograph the building and comment on the beauty of its architecture.

The geographical location of an agency might seem to be a minor detail. But here it is a question of marketing. The fact that the agency is situated in Clichy conveys values subsequently taken over and adapted in economic terms. These values are then nurtured for the benefit of the agency's public image. Clichy Extensive, like the accompanying booklet, helps to increase the values of the agency's activity. This display of values is a symptom of management's desire to show that advertisers can have ethics, that they favour human and positive values. Moreover, my entry into DVL in order to conduct fieldwork was largely in tune with the agency's business ethics. The managers were thrilled by anthropology because it corresponds to a system of values that they wanted to spread. To recruit an anthropologist in an environment dominated by secrecy and confidentiality was a demonstration of their open-mindedness and intellectual curiosity. Of course, it is also possible-even probable-that these advertising executives hoped that the anthropologist could improve the reputation of the advertising profession as a whole.

In short, we are dealing with an advertising agency that advertises for itself. The agency therefore plays with a certain ethics of the advertising profession and the way they are used as a communication tool, both for marketing purposes and for the benefit of the agency, as they reveal the values of the agency in order to attract other clients. It seems that the employees of DVL, far from hiding their marketing of 
ethics, openly recognise the nature of this practice. However, the fact that a marketing logic is accepted does not necessarily indicate a lack of values or cynical hypocrisy on their part. Although ethics can be seen as being able to increase the firm's capital (whether symbolic or financial), we should not automatically assume that the moral values put forward by employees are false. Ghislaine Gallenga asks the question: "can one speak of business ethics without falling into the ethics trap of thinking, that is to say making a personal judgment, about the cause or the actual outcome of the impact of ethics in the business world? How should we regard these moral categories in their intention to sincerity or authenticity from an anthropological point of view?" (Gallenga 2013: 29). Taking Kant's formulation of ethics, that an action should be accomplished in a desire to be ethical and not with a view to making profits (Kant 1795), we are not dealing here with a question of repudiating the moral values proclaimed by the staff of DVL; nor are we judging or assessing their relevance or their veracity. This is not the role of the anthropologist, and it is probably pointless to try to discover if the aim of the ethics advocated is real or not. The intentionality of ethics, moreover, can be twofold (a combination of an ethical will and the pursuit of profit, for example).

\section{A moral way to advertise}

DVL claims to exemplify a certain "philosophy"8 in a work tool called "disruption," the aim of which is to develop an intensive creativity in order to be distinguished in the advertising market. This method demonstrates an alignment strategy with regard to the agency's corporate culture and unites its employees, comprising the identification of "ready-made slogans" by studying the brand's field in order to find more original ideas that can successfully express what the brand aims to say of and for itself. The idea, finally, is to express something different, by reviewing previous advertisements devised by rival agencies, in order to point out which conventional ideas should be avoided. This method is rooted in an ethical vision of the advertising profession, exemplified by the agency through its business ethics: the values of the agency are displayed symbolically, for example, through the organisation of events like Clichy Extensive or with the graffiti on its entrance.

The agency's method combines commercial logic (a way for the brand to become understandable more efficiently) and a moral use of advertising: the agency's employees comply with this method daily with a view to improving their work by producing "better advertisements" and compare the activity of their own agency with what they call "bad advertising agencies" which do not seek to be original. Through business ethics, the employees of DVL show their intent to do their job well by

${ }^{8}$ DVL employs this term of "philosophy." 
conforming to ethics and by showing that they have values. ${ }^{9}$

So far as DVL is concerned, the objective is all the more important for employees in a world specifically open to social criticism (Klein 2001; Amalou 2001-to name but two authors in an abundance of antiadvertising literature and associations such as Casseurs de pub and Résistance à l'oppression publicitaire). My informants presented advertising as a highly criticised world. Judith confided to me: "my family thinks that my job is 99 Francs," citing a well-known book exposing the French advertising industry. ${ }^{10}$ Agnès pursued this idea, affirming that the advertising world is held responsible for present-day consumer society. She added that this vision was full of clichés deriving from the 1980s. The Sapin law of 29th January 1993 introduced compulsory anti-corruption measures for transparency in media buying and politics. The French government introduced this law because before then, especially in advertising agencies and among the clients, billing practices were not regulated and often did not correspond to the actual provision of services.

The advertising profession is often denounced as being amoral-willing to sell anything at any price. This idea would suggest that ethics would be an ideal or a model of perfection to which advertising executives could never aspire. However, I suggest that the employees' ethics are an element that can be negotiated, and that they are not something rigid. Indeed, Timothy de Wall Malefyt and Robert J. Morais (2012), both of whom have worked in advertising companies, show their ethical dilemmas. For instance, they recognize themselves as having social responsibility for consumers, but at the same time as working for a company and being constrained by business necessities. Ethnography is used by advertisers as a tool for making advertising more efficient. Anthropologists work with advertising people, and a key priority is to protect the consumer from harmful ads. Malefyt and Morais (2012: 129) write:

Our contribution as anthropologists lies in accessing unprecedented and often deeper consumer input than is obtained by other marketing research techniques. In this sense, we enable consumer co-creation of brand innovation. We also know and accept that we are occasionally complicit with advertisers in the manipulation of consumers (...) As we listen to our clients' demands for more compelling

\footnotetext{
${ }^{9}$ In his book, A Japanese Advertising Agency, Brian Moeran mentions the business philosophy of a Japanese advertising agency "as providing the best possible service to its clients" (Moeran 1996:74). Here, the important value of the agency, in which lie its employees' ethics, is to be fair to its clients.

1099 Francs is a novel by Frederic Beigbeder (2000) openly denouncing the advertising world. He was subsequently dismissed from his creative position at the Young \& Rubicam agency.
} 
advertising, we nod our heads, smile, and, unless we believe the client's claims are patently false and harmful for consumers, we accept the call for action.

In short, DVL tries to show that it is possible to advertise properly in a "fair" way. One can consider the employees as being placed in a double bind situation (Bateson 1956), since they must reconcile moral values with economic demands-two spheres presumed to be contradictory. They have to negotiate with their own system of values while being subject to financial and wage constraints of the firm that employs them.

It is customary for advertising agencies to conduct campaigns for charitable organizations without being paid a fee. If this charity work does not bring in much-or any-money for the agencies, the gain is still symbolic. These more "noble" clients equalise the scales such that clients who bring in high fees may be of poorer quality on a moral scale. Charitable activities and contacts, on the other hand, bring in moral prestige and enhance the image projected by and of the advertising agency, which works for a client (charity) who has moral values: helping the poor most of the time. It is added value for the agency, since such work stimulates creative ideas among employees precisely because the financial aspect of the account is less important. There is, then, more freedom than with a bigger client such as a food producer or automobile firm. Charity adds a moral dimension to the advertising work and affords employees pleasure because they are less tied to the economic and financial logic of their profession.

Claire, who has worked for seven years in the account services department, is a specialist in branding strategies. She was very hesitant when I asked her questions about the agency's political engagement: "You know, humanitarian subjects are very important for the agency; they are its window display." Business ethics is the showcase of an agency, therefore, and is intended to broadcast the fact that "it is our job to help associations with moral values [helping people in need, and so on]."

The agency's job of communication could therefore be analysed as a means of visualizing the ethical frameworks of the profession. It concerns putting forward ethics and values that are then adapted to the agency's working methods. Day by day, the two employees attached to the PR department produce ethics in their actions. They see themselves as guardians of the values inherited by the imagined "corporate culture," mobilising and representing them in their work practices. Thierry Pillon (2011: 6) stresses the fact that employees in all professions "develop a know-how and methods adapted to place and circumstances. Their inventiveness deploys within a moral economy fixing the boundaries between the acceptable and the intolerable, between what is enhanced and, on the contrary what is rejected, allowed and forbidden." 
The method of communication peculiar to DVL lies in the demonstration of the agency's values, to make them live and act in a certain way. It is the performative action of the firm's communication as "deliberate deployments of expressive abilities in front of a public" (Winkin 2001:269). But it is also the performative action of advertising itself. In his book How to Do Things with Words, Austin writes: "the ethical proposals, for example, may aim to show an emotion or to advocate a form of behaviour, or to influence behaviour in some way" (1970: 38). Thus, the performative "indicates that to formulate an enunciation is to accomplish it" (ibid.: 42). The work of the PR department consists of advertising "about and for advertising" (Cochy 2011: 145). Indeed, as an advertising agency, DVL applies to itself the know-how that it sells to firms. The work of the agency, in fact, is to play with codes, values and images so that their client firms can pass on their messages to customers. DVL does not employ an agency to do its own advertising. It does this job itself.

Through the values displayed by business ethics, then, the agency's managers hope to be able to show more extensively that as advertising executives they, too, have ethics. For example, in 2012, the agency managed the election campaign for François Hollande, France's current president. Those taking part in the campaign did so of their free will. No team was designated by the management for the project. For example, Richard, director of the creative department, chose not to work on the project. He said to me: "Politics and advertising have nothing to do with each other-otherwise it becomes propaganda." In this way, Richard expressed both his ethics as an employee and his personal convictions. He showed that, as an ad man, he had ethics. This flexibility allows employees to withdraw from a project when they get to a point where they cannot reconcile their personal values with the job of advertising.

\section{Conclusion}

The analysis of DVL's business ethics highlights both the values displayed by the agency and also the moral aspects attached to advertising practices as professional standards. The business ethics of DVL, in my opinion, is a matter of conciliation-a happy medium between moral values and economic requirements peculiar to the business world. Business ethics is the key term that justifies their activity. In fact, advertising executives rely on ethics to increase the standing of their profession by displaying the ethical dimensions of their work. It is a means of giving morality to a profession that is considered not to be moral. Executives display ethics as the existence of good practice in their profession, and their moral decisions show their vision of what good practice in fact is. The analysis of what business ethics covers for individuals brings advertising work practices to light and makes it possible to understand the dialectic 
between individual and collective.

So far as individuals are concerned, it is useful to conceive of ethics as a space of adjustment. Ethical considerations arise when an individual asks himself what attitude to adopt in front of a given situation. In social sciences, ethics can be seen as an interstice, a space of choice upon which depend the estimation and the negotiation of "wiggle room" (Massé 2009a, 2009b). The ethics of DVL's employees can be a compromise between their emotions and the principles of the economic world, but one should not neglect the individual aspect of ethics that come up against or support the ethics negotiated by employees. The ethics of the employee is a space of negotiation between the self and the self at work. Ethics is therefore not a system of values but a moment of compromise between different systems of values.

\section{References}

Amalou, F. 2001. Le livre noir de la pub. Quand la communication va trop loin. Paris: Stock.

Austin, J. L. 1970 [1962]. Quand dire c'est faire. Paris: Éditions du Seuil. Bartoli, A., P. Hermel 1986. Piloter l'entreprise en mutation. Une approche stratégique du changement. Paris: Éditions d'organisation.

Bateson, G. 1956. Toward a theory of schizophrenia. Behavioral Science 1 (4): 251-254.

Beigbeder, F. 2000. 99 francs. Paris: Éditions Grasset et Fasquelle.

Both, A. 2007. Les managers et leurs discours. Anthropologie de la rhétorique managériale. Bordeaux: PUB.

Cochoy, F. 2011. De la curiosité. L'art de la séduction marchande. Paris: Armand Colin.

Gallenga, G. 1993. La notion de culture d'entreprise dans la littérature managériale. Une critique ethnologique. L'Uomo 6 (1 \& 2): 135-147.

Gallenga, G. 2013. L'éthique entrepreneuriale: un objet anthropologique ? Moussons 21: 21-36.

Hessel, S. 2011. Time for outrage! Translated by D. Searls and A. Arrikha. London: Quartet Books.

Kant, E. 2000 [1785]. Fondements de la métaphysique des moeurs. Paris: Hatier.

Klein, N. 2001. No logo. Paris: Actes Sud. 
Lallement, E. 2005. Le populaire à l'épreuve des situations marchandes: "popu-chic" et "chic-popu" chez Tati. Hermès 42: 131- 136.

Malefyt, T. de Waal and Morais, R. 2012. Advertising and anthropology: ethnographic practice and cultural perspectives. Oxford: Berg.

Massé, R. 2009a. Présentation: l'anthropologie face à la morale et à l'éthique. Anthropologie et Sociétés 33 (3): 7-19.

Massé, R. 2009b. Anthropologie des moralités et de l'éthique: essai de définitions. Anthropologie et Sociétés 33 (3): 21-42.

Moeran, B. 1996. A Japanese advertising agency: an anthropology of media and markets. London: Curzon.

Palumbo, M.A. 2014. Barbès, Château Rouge, Goutte d'Or. Ailleurs commence ici. Anthropologie d'un espace d'altérité dans Paris. Doctoral dissertation. Paris. EHESS.

Pillon, T. 2011. Présentation in "Travailler." Communications 89: 5-8.

Salmon, A. 2004. L'offre éthique des entreprises. Cahiers internationaux de sociologie 1 (116): 77-96.

Salmon, A. 2009. Moraliser le capitalisme? Paris: Cnrs éditions.

Winkin, Y. 2001. Anthropologie de la communication. Paris: Éditions du seuil.

Léa Porée studies social anthropology. She has a Master's degree from Aix-Marseille University. Her research focuses on French advertising agencies and especially the moral aspects of the profession. She can be reached at poree.lea@hotmail.com. 